\title{
Differences in selected areas of social capital regarding residence
}

\author{
Angela Almasiova, Katarina Kohutova, and Zuzana Gejdosova \\ Catholic University in Ružomberok, Slovakia
}

\begin{abstract}
Introduction. In addition to a massive increase in interest in the concept of social capital in the social sciences, the research has shown its considerable impact on various areas of human life. OECD points to the correlation between social capital and health and points out that social isolation is associated with misery and disease. Aim. The contribution aims at pointing out the differences in selected indicators of social capital, focusing on the participation and social involvement of respondents in their place of residence. Results. Quantitative research was conducted using the questionnaire method, which was compiled from the Social Capital Question Bank database, covered by the UK Statistical Office. Result Cluster analysis divided respondents into those with higher and lower social capital, and comparative analysis showed significant differences in selected indicators of social capital between urban and rural respondents. Conclusions. Respondents from cities and rural areas differ in the level of social capital in our areas of interest: Participation or involvement in local groups, Political activity or voting, Taking positive action about a local issue, Participation in religious activity, Completed or received a practical favour, Familiarity with neighbourhood, Provide regular service, help or care for others.
\end{abstract}

Key words: social capital, participation, social involvement.

\section{Selected aspects of social capital}

The present paper is primarily concerned with the question of whether there are differences in social capital concerning the person's place of residence. Why is it of any relevance to look at these differences? It results from the very character of the place of residence of the personthe countryside is characterized by less social control, less access to public services, lack of employment, etc., and, on the other hand, a city with much more anonymity is associated with weak social control, a much faster way of life strongly linked to employment. However, as Giddens [1] points out, the city can sometimes take a "new human being" much friendlier than a countryside where a long-term established community and neighbourhood can be unavailable for a long time for the new individual. The difference between the countryside and the city also concerns the bonds between the people and thus also the social capital itself.

In trying to organize the definition of social capital, we should base it on its two basic forms of perception - individual and collective, depending on who benefits from the sources of capital. Some authors perceive it at an individual level [2-4], or collective level [5, 6].

One of the leading representatives of the perception of social capital at an individual level is Pierre Bourdieu, who perceives it as an "aggregate of current or potential resources that are based on ownership of a sustained network of more or less institutionalized relationships and acquaintances, in other words, group membership that equips each member with collectively 
owned capital, that is, with different entitlements [2]. The author argues that the baseline of any capital is the economic capital, but in order to understand the social world, it is necessary to understand all forms of capital, not only the economic one. For economic capital, Bourdieu considers capital in the traditional perception of this word - the various forms of material wealth - not just the possession of means of production. It is possible to "transform" it into real power only if it is associated with other forms of capital - social and cultural [8].

Another significant figure of the perception of an individual form of social capital is James Coleman [7], which is mainly associated with the theory of rational choice and its instrumental view of the behaviour of people in order to maximize profits. He defined social capital as ... "standards, social networks, and relationships between adults and children that are a value within childhood. Social capital exists in the family but also outside of the community and also serves to maximize its profit". Another dimension of social capital was provided by Robert Putnam [6] who also "levelled" it to the macro-social level in the public sphere-especially in the politics and functioning of democracy in general: “... social capital refers to the characteristics of a social organization, such as trust, standards, and networks that facilitate coordinated behaviour and thus contribute to the company's performance".

Since our paper is devoted to social capital in the context of the size of the human capital, we will focus on perceiving this dimension of social capital. The author mentioned above, Putnam [6] states that social capital depends on the size of the community in which a person lives. He claims that altruism, volunteering, philanthropy, participation in community projects, helping foreigners, participation in charity projects are more common in smaller communities than in big cities. In the case of church attendance and membership in church organizations, rural residents are more involved than inhabitants of the city (10\%$20 \%$ difference). In the countryside there is 30-40\% higher chance of people becoming members of interest or other organizations than in the city. Putnam claims that people from the city are less committed not because of who and how they are, but because of where they are. Neighbourhoods with a high level of social capital tend to be suitable places for child upbringing, public spaces are cleaner, people are more friendly, and the streets are safer. Research conducted with pregnant women has shown that women living in smaller neighbourhoods with more considerable social capital perceive their health as better compared to women living in larger neighbourhoods with smaller social capital [9].

\section{The goal of the research and key hypothesis}

The goal of the research is to identify the extent of social capital in selected areas and to compare it between urban and rural respondents. Based on the facts above, we assume that there are significant differences in selected areas of social capital due to the size of the residence (up to 1,000 inhabitants, from 1001 to 5000 inhabitants and over 5001 inhabitants).

\section{Research sample}

The research sample consisted of 381 respondents, of whom 117 were men (30.7\%) and 264 women $(69.3 \%)$. The median age of the research file was 40.6 years (SD 13.24 years). The youngest respondent was 18 years old, the oldest 72 years old. Secondary education with a leaving exam ( $\mathrm{N} 138,36.2 \%)$ and higher education (N 132, 34.6\%) prevailed. To a lesser extent, we also counted respondents with secondary education without leaving exam ( $\mathrm{N} 87$, $22.8 \%$ ) and respondents with elementary education, those were $24(6.3 \%)$.

Regarding marital status, married respondents ( $\mathrm{N} 222,58.3 \%$ ) prevailed, followed by single/single ( $\mathrm{N} \mathrm{123,32.3 \% )}$ and least respondents were divorced ( $\mathrm{N} \mathrm{21,5.5 \% ).} 15$ respondents marked option "other." 
An important variable was also the size of the residence where the respondent lives. 114 respondents $(29.9 \%)$ lived in a place up to 1,000 inhabitants, 138 respondents (36.2\%) lived in a residence of 1001 to 5000 inhabitants, and 120 respondents $(31.5 \%)$ lived in a residence of over 5001 inhabitants. 9 respondents did not respond.

\section{Research method}

Respondents were asked to submit a questionnaire consisting of 18 items devoted to different areas of the social capital. 5 items surveyed demographic characteristics of respondents. The items in the questionnaire were selected from the Social Capital Question Bank ${ }^{1}$ database on social capital.

We have observed 6 areas of social capital related to Participation, social engagement and commitment: Participation or involvement in local groups, Political activity or voting, Taking positive action on a local issue, Participation in religious activities, Completed or received a practical favour, providing regular service, help or care for others.

The data were analyzed using IBM®SPSS (version 22), and descriptive and inductive statistics were used for statistical analysis (Mann-Whitney U-test, Kruskal-Wallis Test).

\section{Results}

In the result section, we are gradually presenting the analysis of the six focused areas. Each area consisted of several questions in the questionnaire, and we created a compound variable from these items. We continued to work with this variable, and we found differentiations in it concerning the size of the respondent's residence within the framework of the research questions.

\subsection{Participation or involvement in local groups}

The area mentioned above of social capital has been identified with three items: a) How often have you visited a group, association, club or religious institution for the last year to ask for help or just for joy, sport, relaxation and more? b) How often in the past year have you helped an organization - school, hospital, jail, charity, volunteer organization? c) Are you currently a member of one of the following organizations: political party, trading company; environmental society ${ }^{2}$, etc.?

From the items mentioned above regarding participation in local groups, we created a compound variable $\mathrm{e}^{3}$. It is true that if the respondent has more points in this area of the social capital, his/her participation in local groups is higher. Respondents could have reached a minimum of 0 points (if they answered the first two questions as "never" and are not members of any organization), and a maximum of 29 points (if they would answer "two times a week" and would be a member of all organizations). 39 respondents had a minimum possible value of 0 points, while the maximum was 17 points, which was reached by 3 respondents. The average level of participation in local groups was 3.74 points (SD 3.35).

\footnotetext{
${ }^{1}$ The Social Capital Question Bank is an extensive database of suggestions for making its own methodological proposals for social capital research, which is covered by the UK Office for National Statistics. The database consists of 5 areas of social capital: 1. Participation, social engagement, commitment, 2. Control, self-efficacy, 3. Social interaction, social networking, 5. Trust, reciprocity, social cohesion. In our research we deal with part 1.

${ }^{2}$ A brief description of answers to individual questionnaire questions is presented in the discussion.

${ }^{3}$ Sum of items 1,2,3. Scaling of question no. 1 and 2 : never $=0$, in the last year three-four times $=1$, every second month $=2$, etc., scaling of question no. 3 : membership in the organization yes $=1$, no $=0$.
} 
Table 1. Differentiation in participation or involvement in local groups relative to the size of the homeplace.

\begin{tabular}{|c|c|c|c|c|c|c|}
\hline & $\mathbf{N}$ & Mean Rank & Mean & $\chi^{2}$ & df & Sig. \\
\hline Up to 1000 inhab. & 114 & 199.72 & 3.45 & \multirow{3}{*}{9.2417} & \multirow{3}{*}{2} & \multirow{3}{*}{0.010} \\
\hline From 1001 to 5000 inhab. & 138 & 196.64 & 3.91 & & & \\
\hline Above 5001 inhab. & 120 & 162.28 & 2.34 & & & \\
\hline
\end{tabular}

Table 2. Differentiation in political activity or voting regarding the size of the place of residence.

\begin{tabular}{|c|c|c|c|c|c|c|}
\hline & $\mathbf{N}$ & Mean Rank & Mean & $\chi^{2}$ & df & Sig. \\
\hline Up to 1000 inhab. & 114 & 200.87 & 9.63 & \multirow{3}{*}{6.256} & \multirow{3}{*}{2} & \multirow{3}{*}{0.044} \\
\hline From 1001 to 5000 inhab. & 135 & 177.93 & 8.69 & & & \\
\hline Above 5001 inhab. & 114 & 167.95 & 8.32 & & & \\
\hline
\end{tabular}

RQ1: Is there a significant difference in the area of participation in local groups due to the size of the residence place?

Based on the significance values, we can say that there is a significant difference between groups (Table 1). Further testing of the differences between groups has shown that there is no significant difference between residents living in the population of up to 1,000 and between 1001 and 5,000. A significant difference was only among the population of over 5001 respondents compared to the two groups mentioned. Thus, we can say that there is a significant difference in the participation in local groups of respondents living in the residence of over 5001 inhabitants compared to the other two groups. Based on the values of the median and the average ranking, respondents living in areas of over 5001 inhabitants are significantly participating lower in local groups compared to those living in areas below 5,000 inhabitants.

\subsection{Political activity or voting}

Political activity and election participation were identified by three items: a) Did you take part in the elections? b) How likely are you going to participate in the next election in the future? c) Please, indicate to what extent it is crucial for you to participate in municipal elections/municipal authorities.

Just as in the previous case, we have created a composite variable from the items mentioned above on political activity and election participation. ${ }^{4}$ It is true that when the respondent has more points in this area of the social capital, their political activity and participation in elections are higher. ${ }^{5}$ The average domain value of political activity and participation in the election was 8.81 points (SD 3.59).

RQ2: Is there a significant difference in the area of political activity and participation in elections based on the size of the place of residence?

Based on statistical test we can say that there is a significant difference between groups (Table 2). Further difference testing has shown that there is no significant difference between

\footnotetext{
${ }^{4}$ Sum of items 1, 2, 3. Scaling of question no. 1 and 2: yes $=1$, no $=0$; Scaling Question \# 3: important $=2$, not important $/$ not important $=1$, not important $=0$.

5 Theoretically, respondents could reach at least 0 points, reaching a maximum of 13 points. In fact, 12 respondents had a minimum possible value of 0 points, while a maximum of 12 points was reached by 132 respondents.
} 
Table 3. Differentiation in taking positive action about a local issue regarding the size of the place of residence.

\begin{tabular}{|c|c|c|c|c|c|c|}
\hline & $\mathbf{N}$ & Mean Rank & Mean & $\chi^{2}$ & df & Sig. \\
\hline Up to 1000 inhab. & 111 & 194.65 & 1.16 & \multirow{3}{*}{7.93} & \multirow{3}{*}{2} & \multirow{3}{*}{0.019} \\
\hline From 1001 to 5000 inhab. & 135 & 186.60 & 1.13 & & & \\
\hline Above 5001 inhab. & 114 & 159.50 & 0.84 & & & \\
\hline
\end{tabular}

residents living in the place with a population of 1001-5000 and over 5001 inhabitants. A significant difference was only among residents up to 1000 respondents compared to the two groups mentioned.

From median values and average ranking, respondents living in areas under 1000 inhabitants have significantly higher levels of political participation and election participation than those living in areas of over 1001 inhabitants.

\subsection{Taking positive action about a local issue}

The third area consisted of the following two items: a) Have you performed any of the following activities in the last 12 months to solve the problem affecting people around you? $\mathrm{b}$ ) Have you been in contact with a member of the municipal council in the last 12 months? We have created a compound variable from these items. ${ }^{6,7}$ The average domain value of political activity and participation in the election was 1.04 points (SD 1,086).

RQ3: Is there a significant difference in active participation in local affairs due to the size of the home place?

Based on statistical test Table 3 shows that there is a significant difference between groups. Further testing of group differences has shown that there is significant difference between residents living in the population of up to 1,000 and between 1001 and 5,000. A significant difference was only among the population of over 5001 respondents compared to the two groups mentioned.

Based on the values of the median and the average ranking we can state, that respondents living in areas over 5001 inhabitants have a significantly lower rate of active participation in local affairs than those living in areas of up to 5,000 inhabitants.

\subsection{Participation in religious activity}

This section concerned one item in the questionnaire, namely: How often, if any, are you attending worship or religious meetings?

RQ4: Is there a significant difference in participation in religious activities due to the size of the home place?

Table 4 shows differences. Further testing of group differences has shown that there is no significant difference between residents living in the place with a population of up to 1,000 and between 1001 and 5,000. A significant difference was only among the population of over 5001 respondents compared to the two groups mentioned. From the values of the median and

\footnotetext{
6 Sum of items 1 and 2. Scaling of questions: yes $=1$, no $=0$.

${ }^{7}$ It is proven that if the respondent has more points in this area of social capital, his active participation in local affairs is higher. Theoretically, respondents could reach at least 0 points, reaching a maximum of 9 points. In fact, up to 147 respondents could reach a minimum of 0 points, while a maximum of 4 points was reached by 15 respondents.
} 
Table 4. Differentiation in participation in religious activity relative to the size of the place of residence.

\begin{tabular}{|c|c|c|c|c|c|c|}
\hline & $\mathbf{N}$ & Mean Rank & Mean & $\chi^{2}$ & df & Sig. \\
\hline Up to 1000 inhab. & 111 & 192.54 & 3.32 & \multirow{3}{*}{38.276} & \multirow{3}{*}{2} & \multirow{3}{*}{0.000} \\
\hline From 1001 to 5000 inhab. & 135 & 207.67 & 3.44 & & & \\
\hline Above 5001 inhab. & 114 & 136.61 & 2.53 & & & \\
\hline
\end{tabular}

Table 5. Differentiation in completed or received practical favour.

\begin{tabular}{lllllll}
\hline & $\mathbf{N}$ & Mean Rank & Mean & $\chi^{\mathbf{2}}$ & df & Sig. \\
\hline Up to $\mathbf{1 0 0 0}$ inhab. & 111 & 174.18 & 3.27 & & & \\
\cline { 1 - 4 } From 1001 to 5000 inhab. & 138 & 212.36 & 3.87 & & 2 & $\mathbf{0 . 0 0 0}$ \\
\cline { 1 - 4 } Above 5001 inhab. & 120 & 163.55 & 2.95 & & & \\
\hline
\end{tabular}

the average ranking, respondents living in areas over 5001 inhabitants have a significantly lower rate of participation in religious activities than those living in areas of up to 5,000 inhabitants.

\subsection{Completed or received a practical favour}

The fifth area consisted of the following three items: a) Have you done any kind of favour to your neighbour in the last 6 months? b) Has any of your neighbours made a favour to you in the past 6 months? c) Select what you have been given free of charge in the last 12 months. Please exclude family members and relatives. From the items mentioned above regarding accepted or delivered kindness, we have created a composite variable. ${ }^{8,9}$ The average value of domain received and given favour was 3.37 points (SD 1,823).

RQ5: Is there a significant difference in giving or receiving favour concerning the size of the place of residence?

Based on the result of statistical tests we can say that respondents living in areas of 1001 to 5,000 inhabitants have a significantly higher rate of providing and receiving kindness than those living in areas of up to 1,000 inhabitants and over 5001 inhabitants.

\subsection{Provide regular service, help or care for others}

The sixth area consisted of the following three items: a) Do you provide regular services or assistance to an ill person, a disabled person or an elderly person who does not live with you? b) Have you made any of these activities free of charge in the last 12 months for a person who is not your relative? c) Have you helped someone or provided any help for someone who is not a member of your household for the last 4 weeks? We have created a compound

\footnotetext{
8 The sum of items a), b) c). Scaling questions: yes $=1$, no $=0$.

${ }^{9}$ It is proven that if the respondent has more points in this area of social capital, that is his activity in giving or receiving favours is higher. Theoretically, respondents could reach at least 0 points, reaching a maximum of 14 points. In fact, 36 respondents had a minimum of 1 point, while the maximum was 13 points, which was 3 respondents.
} 
Table 6. Differentiation in provide regular service, help or care for others.

\begin{tabular}{|c|c|c|c|c|c|c|}
\hline & $\mathbf{N}$ & Mean Rank & Mean & $\chi^{2}$ & df & Sig. \\
\hline Up to 1000 inhab. & 111 & 144.05 & 2.27 & \multirow{3}{*}{26.718} & \multirow{3}{*}{2} & \multirow{3}{*}{0.000} \\
\hline From 1001 to 5000 inhab. & 138 & 211.54 & 3.39 & & & \\
\hline Above 5001 inhab. & 120 & 192.35 & 2.80 & & & \\
\hline
\end{tabular}

variable from these items. ${ }^{10,11}$ Average Domain Value Regular Assistance/Service/Care for Others was 2.83 points (SD 2,025).

RQ6: Is there a significant difference in the regular provision of help/service/care relative to the size of the home place?

Based on the results of relevant statistical tests we can say that respondents living in areas of up to 1,000 inhabitants have a significantly lower rate of regular assistance/care/care compared to those living in areas above 1001 inhabitants.

\section{Results evaluation and discussion}

The research aimed to identify the level of social capital in selected areas and to compare it between urban and rural respondents. From the theoretical analysis and conducted research, there are significant differences in the social capital of the inhabitants of smaller and larger settlements, or between rural and urban residents [10]. Also, rural residents are characterized by a more significant number of social interactions than urban residents [11]. Our research did not investigate the impact of social capital on human health, but a study that observed the effects of social capital in 45 countries showed a significant direct relationship between the amount of social capital and human health [12]. For this reason, we conducted our research.

Based on this fact we assumed that there are significant differences in selected areas of social capital due to the size of the home place.

The first observed area was the rate of participation in local groups. Three items measured this area. The first item was focused on visit of a group, association, club or religious organization because of the support for somebody (or just for fun, relaxation, ...) last year, while the descriptive analysis showed that $19 \%$ of respondents never realized such a visit, on the contrary almost half did it three or four times in the last year. Other respondents $(34 \%)$ did it several times over the last year (e.g., several times a month or a week). Furthermore, under the second item in the questionnaire, we found out that $39.2 \%$ of the respondents never realized the help to any organization (e.g., school, charity, hospital), but $42.2 \%$ realized it in the last year at least 3 to 4 times. Other respondents (18.6\%) reported a more frequent frequency of assistance. The third question in this area was whether the respondent was a member of an organization. We found that most respondents are members of voluntary organizations (24.6\%), followed by membership in sports clubs $(21.3 \%)$, religious organizations $(19.7 \%)$, retiree organization $(18 \%)$, professional organization or other organization, a school parent organization and a business company (in the last four cases, $11.5 \%$ of the respondents reached the same share). Below $10 \%$ of respondents were the members of a general organization, a neighbourhood organization, a women's organization,

\footnotetext{
10 The sum of items a), b) c). Scaling questions: yes $=1$, no $=0$.

11 It is proven that if the respondent has more points in this area of social capital, his or her assistance, service or care for others is higher. Theoretically, respondents could reach at least 0 points, reaching a maximum of 14 points. In fact, 6 respondents achieved a minimum possible value of 0 points, while the maximum was 11 points, which was reached by 3 respondents.
} 
a social club for men and a youth organization. From these items, we compiled a composite variable named Participation or involvement in local groups, and we compared the overall score in this area to the size of the respondent's residence place. We can say that respondents living in bigger cities (over 5,000 inhabitants) are less involved in local affairs.

The second area concerned political action or voting and was measured by three items. From the descriptive analysis of the items, $80.3 \%$ of the respondents participated in the parliamentary elections, $75.6 \%$ of the respondents participated in the municipality elections, $74 \%$ of the respondents took part in the election of the President, $45.7 \%$ participated in elections when voting for members of EU Parliament and $62.2 \%$ of respondents participated in the elections in self-governing regions. The second question, if the respondents are planning to participate in the next elections, was answered positively by $81.1 \%$ in the case of parliamentary elections, $77.2 \%$ in the municipal elections, the election of the President was planned to be attended by $78 \%$ of the respondents, $57.5 \%$ of the respondents for the elections to EU Parliament and for the bodies of the self-governing regions it was $66.1 \%$ of the respondents. The third item, concerning the importance of participation in the municipal elections, was answered by $70.9 \%$ of the respondents, who consider it was important, 19.7 did not consider it significant but not insignificant, and 6.3\% said it was irrelevant. Overall, we have found that the highest rate of political participation and participation in the elections belongs to the respondents in the smallest villages to 1000 inhabitants.

The third area was aimed at identifying active participation in local affairs, and two items measured it. A descriptive analysis showed that only $2.4 \%$ of respondents mentioned that they approached local newspapers, $8.7 \%$ of respondents contacted the general council, $19.7 \%$ contacted a municipal representative or mayor/responsible person, $13.4 \%$ participated in a civil meeting due to discussion, $0.8 \%$ participated in the protest meeting, $6.3 \%$ helped organize the petition. The second item, which focused on contact with a member of the municipal (village) council, was answered positively by $49.6 \%$ of respondents. By this, we can assume that the Slovak respondents are relatively active in the elections (see results for the previous area), but after the elections, they are no longer actively involved in public affairs. Based on the comparative analysis, the respondents in the smaller villages and towns of up to 5,000 inhabitants are more involved in this area compared to larger cities.

Within the fourth area, focused on participation in religious activities, we found the frequency of visits to religious services or religious meetings. We can say that more than half of the respondents attend worship once a week or even more $(55.9 \%), 16.5 \%$ visit them at least once a month, $13.4 \%$ only during weddings and funerals, $8.7 \%$ at least once a year and $2.4 \%$ never or almost never. We also found that higher rates of participation in religious activities are among respondents living in smaller villages and towns of less than 5,000 inhabitants.

The fifth section was related to accepted or provided favour and was measured by three items in the questionnaire. The descriptive analysis showed that $85 \%$ of the respondents had done the favour for the neighbour in the last 6 months, and $70.1 \%$ of the respondents received help from the neighbour. As a free help or support, $40.9 \%$ of the respondents mentioned free assistance, $18.1 \%$ of respondents received it in the form of shopping or mail assistance, $15.7 \%$ of respondents in the form of cooking or household duties, in the form of home repairs (e.g., painting, car repair) $11.8 \%$ of the respondents, babysitting was mentioned by $13.4 \%$ of respondents, support with dressing or doing basic hygiene for $7.1 \%$ of the respondents, $40.2 \%$ of the respondents got the advice, the help with the official affairs claimed $3.9 \%$ of the respondents, representing with official instances $2.4 \%$ of respondents, transport assistance for $16.5 \%$ of respondents and $2.4 \%$ of respondents claimed that they got another form of support. Comparative analysis has shown that the most active and engaged in this area are respondents living in areas from 1,000 to 5001 inhabitants. 
In the sixth section, we focused on the rate of regular service, assistance, or care for others. Three items were measured, with a descriptive analysis showing that a regular service or assistance to a sick, disabled or older adult who does not live with the respondent was provided by $11 \%$ of the respondents. $70 \%$ of respondents assisted someone who is not a member of their household for the last 4 weeks. As a free help to a non-relatives, $59.8 \%$ of the respondents provided support in form of regular contact, in the form of shopping or mail assistance $15 \%$ of respondents, in the form of food preparation or household duties $18.1 \%$ of respondents, in the form of home repairs (painting, car repair) $9.5 \%$ of respondents, $12.6 \%$ of respondents provided assistance in the form of childcare, $9.4 \%$ of respondents provided help with washing or dressing, $41.7 \%$ gave advice, $1.6 \%$ guarded the household or house pet, official assistance (filling in forms, etc.) was provided by $9.4 \%$ of respondents, representing with official instances by $6.3 \%$ of respondents, transport assistance, accompanying somebody by $11 \%$ of respondents and $5.5 \%$ of respondents offered another type of help. Comparison analysis showed that social capital in this area is the lowest among respondents living in municipalities under 1000 inhabitants.

\section{Conclusion}

The results of the study presented by us are aligned with the results of the authors mentioned above, who have mentioned the differences between social capital in smaller and bigger settlements, in the city and the countryside. In all of our social capital areas surveyed, respondents from smaller venues reached higher values. The reason we have identified these differences is that social capital, among other things, affects human health and its quality of life, so it is necessary to find out what can contribute to the greater well-being of a person.

\section{References}

[1] Giddens, A. Sociologie. Vyd. 1., Praha: Argo, 1049 s. ISBN 978-802-5708-071 (2013)

[2] Bourdieu, P. The forms of capital. In J. Richardson (Ed.) Handbook of Theory and Research for the Sociology of Education (New York, Greenwood), 241-258 (1986)

[3] Narayan, D., Cassidy, M.F. A Dimensional Approach to Measuring Social Capital: Development and Validation of a Social Capital Inventory. Current Sociology. 2001 49(2), 9-102 (2001)

[4] Bjørnskov, Ch., Sønderskov, K. Is Social Capital a Good Concept? Midwest Political Science Association 67th Annual National Conference, Chicago, April 22-25, 2010. Available at SSRN: http://ssrn.com/abstract=1593507 (2010)

[5] Lochner, K., Kawachi, I., Brennan R.T., Buka, S.T. Social capital and neighborhood mortality rates in Chicago. Social Science \& Medicine. Elsevier 56(8), 1797-1805. DOI: https://doi.org/10.1016/S0277-9536(02)00177-6 (2003)

[6] Putnam, R.D. Bowling alone: the collapse and revival of American community. New York: Simon \& Schuster, ISBN 0-7432-0304-6 (2000)

[7] Coleman, J. Social Capital in the Creation of Human Capital. The American Journal of Sociology, 2009 94. Available at: http://courseweb.lis.illinois.edu/ $\sim$ katewill/forchina/readings/coleman $\% 201988 \% 20$ social $\% 20$ capital. $\operatorname{pdf}(1998)$

[8] Šubrt, J., Balon, J. Soudobá sociologická teorie. Vyd. 1. Praha: Grada, 232 s. Sociologie (Grada). ISBN 978-802-4724-577 (2010) 
[9] Lamarca, G., Leal, M., Sheiham, A., Vettore, M. 'The association of neighborhood and individual social capital with consistent self-rated health: a longitudinal study in Brazilian pregnant and postpartum women', BMC Pregnancy \& Childbirth 13(1), 1-17 (2013)

[10] Yang, T., Jensen, L., Haran, M. 'Social Capital and Human Mortality: Explaining the Rural Paradox with County-Level Mortality Data', Rural Sociology 76(3), 347-374 (2011)

[11] Hofferth, S.L., Iceland, J. "Social Capital in Rural and Urban Communities". Rural Sociology 63, 574-98 (1998)

[12] Mansyur, C., Amick, B.C., Harrist, R., Fransini, L. Social capital, income inequality, and self-rated health in 45 countries. Social Science \& Medicine. Elsevier 1(66), 43-56. DOI: 10.1016/j.socscimed.2007.08.015 (2008) 